\title{
Geospatial modeling, analysis and mapping for aerodrome land development
}

\author{
Liudmila Mitsevich ${ }^{1 *}$, and Natalia Zhukovskaya ${ }^{2 * *}$ \\ ${ }^{1}$ State enterprise Belgeodesy, 220029 Masherova avenue17, Minsk, Belarus \\ ${ }^{2}$ Belarusian State University, Faculty of Geography and Geoinformatics, 220030, Leningradskaya \\ street, 16, Minsk, Belarus
}

\begin{abstract}
The article discusses aerodrome geospatial modeling methods and geoinformation analysis for determining land use zones and obstacle restriction areas. Tall trees, buildings and structures, exceeding special limitation surfaces in the aerodrome flight areas, are obstacles that are dangerous. Using spatial modelling, which determines maximal permissible heights, it is proposed to predict the heights of natural and artificial vertical objects in order to analyse and plan land use capabilities. As a basis for spatial modeling, it is proposed to use stereoscopic models with a resolution of $0.3 \mathrm{~m}$, built on aircraft-based scanner images. Using the methods of geoinformation analysis, it is suggested to make horizontal zoning of aerodrome areas according to the most important air navigation safety and ecological indicators (power lines, roads, permitted classes of construction objects location). The study presents the research results of the proposed methodology for the Republic of Belarus aerodrome.
\end{abstract}

\section{Introduction}

The aerodrome area is a territory with special conditions for the land use on the reason flight safety and ecological compatibility. The aerodrome area is divided into zones in the vertical aerodrome airspace and in the horizontal plane.

Vertical zoning is limited by obstacle limitation surfaces (OLS) which determine the maximum permissible obstacle heights for the aircraft flight. OLS extend up to $15.0 \mathrm{~km}$ from the runway thresholds and expand to the air space of the aerodrome (Fig.1).

\footnotetext{
* Corresponding author : mila.skygeo@gmail.com

** Corresponding author : natazhuk@gmail.com
} 


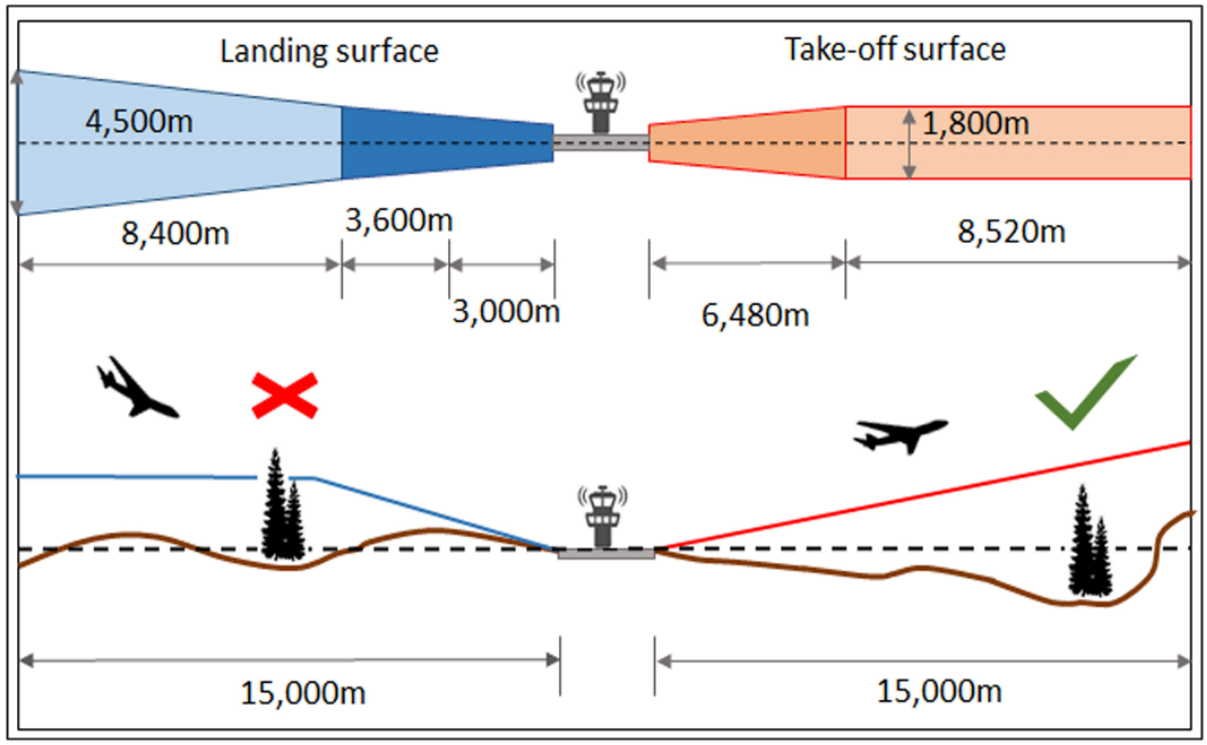

Fig.1. Obstacle limitation surfaces schema (vertical zoning limitations)

The limitation surfaces are built on the air navigation safety rules but always have an individual geometry depending on the aerodrome technical specification (runway quantity, aircraft types, etc.) The rules for the OLS technical calculations are obtained from the regulatory documents of the International Civil Aviation Organization (ICAO) [1].

Horizontal planning depends on the location of the airfield, terrain conditions, landscape features and types of human economic activities. There are zones where construction cannot be carried out, where there are certain limitations on social and environmental aspects, and where there are no restrictions both in the planned and in the high-rise location of vegetation and economy facilities [2].

Horizontal zoning in the aerodrome impact area was carried out in accordance with the guidance of Federal Aviation Administration (FAA) [3]. It is proposed to allocate six zones: Runway Protection Zone (1, RPZ), Inner Safety Zone (2), Inner Turning Zone (3), Outer Safety Zone (4), Sideline Safety Zone (5) and Traffic Pattern Zone (6) (Fig.2). 


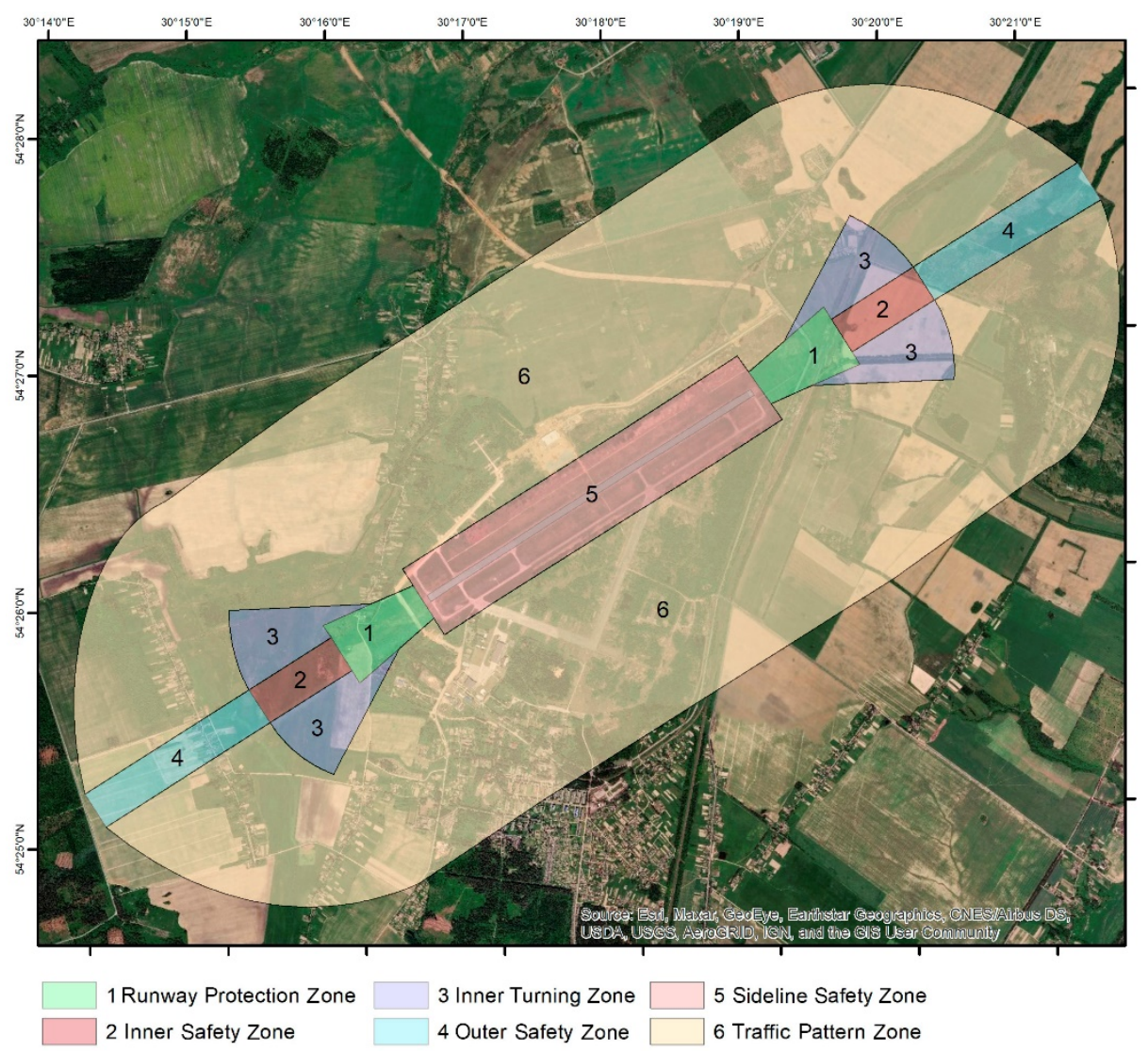

Fig.2. Aerodrome impact zones

Recommended land uses and restrictions are different depending on the particular Airport Impact Zone. So, for RPZ zone is prohibited all new structures and residential land use. In zones 2 and 5 it is recommended to avoid residential land uses but it is allowed low-density (less than five people per acre) industrial development. In Zones 3 and 4 is suggested to limit residential land uses. Industrial and commercial development is permitted with density ranging from 25 to 40 people per acre. Recommended land uses in Traffic Pattern Zone would include low-density residential development and industrial development accommodating fewer than 100 people per acre [3].

The determination of horizontal and vertical zones is carried out both in the planning of new airfields and in the reconstruction of existing ones. During the planning and construction, many factors are taken into account: the terrain elevation, the maximum permissible height of vertical objects and vegetation (artificial and natural obstacles), zones of permissible aircraft noise (construction of residential buildings, infrastructure), electromagnetic and radio radiation (high-altitude power transmission lines, wireless communication) etc.

One of the tasks of aerodrome services is constant monitoring of the tree and bush vegetation heights relative to obstacle limitation surfaces, which is labour and cost intensive but not always effective [4]. In areas where dense forest vegetation has been eliminated, it is necessary to make new plantations in order to avoid soil destruction or the tree uncontrolled growth, which will also be eliminated when certain heights are reached. 
Another problem is the multifaceted consideration of geospatial, economic and social factors on the existing aerodrome territory and when choosing the location of the aerodrome or its reconstruction. Compliance with the rules of air navigation, social and environmental safety requires both rational planning and constant monitoring of objects in the area of aircraft movement.

Research in this area has been carried out mainly on the use of ground or remote sensors to identify existing obstacles. To obtain obstacle data including forest plantations, the most modern sensors were used - lasers, radars, the digital obstacle models were created and methods for their mapping were proposed [5-7].

Horizontal zoning of aerodrome areas for land use purposes is provided for by the ICAO regulatory document [8] and the state air navigation laws. The most recent scientific and methodological zoning studies relates to individual tasks in the aerodrome topographic and geodetic data providing, noise pollution and the allocation of sanitary protection zones [916].

The current research proposes an integrated approach to horizontal zoning, taking into account vertical restrictions, as an essential component in permissible land use within an aerodrome area. The methodology is focused on forecasting and planning the object heights, both natural and artificial, without the need for subsequent vertical monitoring. An integrated solution for obtaining terrain and obstacle data can be the use of spatial earth elevation model and obstacle limitation surface model combined with geoinformation analysis in accordance with the land use allowance and flight safety rules.

The aim of the study was to evaluate the effectiveness of using optical stereo imagery and suggested remote technics for identifying zones on aerodrome area land use and restrictions.

\section{Method}

To create a cartographic vertical and horizontal zoning model, a digital terrain model (DTM), a dense digital model of obstacle limitation surfaces (OLS), and an aerodrome zoning scheme were used to display the combined boundaries of land-use zones.

All geospatial modeling work is performed in a digital photogrammetric system based on the principles of classical photogrammetry [17] and provides both mathematical and geodetic accuracy of all constructed models.

To determine the height limits for vertical objects, a digital model of the maximum permissible obstacle heights was used, obtained by subtracting the altitude of the earth's surface from the altitude of the limitation surface at each point of the work area (Fig. 3.). 


\section{Geospatial data}

\begin{tabular}{|c|c|}
\hline OLS dense model & DTM (bare earth level) \\
\hline Model of the maximum permissible obstacle heights \\
\hline Difference matrix & Contours (1.0m section) \\
\hline Cartographic vertical and horizontal zoning model \\
\hline Horizontal zones & Vertical limitation zones \\
\hline
\end{tabular}

Fig. 3. Technological scheme for creating an aerodrome area horizontal and vertical zoning model

The experimental part of the study was carried out for the territory of the aerodrome ORSHA, Republic of Belarus.

The digital photogrammetric workstation PHOTOMOD 7.0 (Rakurs, Russia), modules for adjusting and processing satellite and aviation images, for vectorization, spatial analysis tools were used for spatial modelling. Toolkit ArcGIS (ESRI) is used for calculations according to the rules of zoning, geoinformation analysis, visualization of cartographic models.

As a basis for spatial digital modelling, the stereo models obtained from images from an aircraft-based ADS-100 scanner (Leica, Switzerland), $0.3 \mathrm{~m}$ per pixel, were used. The exterior orientation elements for aerial photographs are derived from GNSS and inertial navigation data. The final geodetic horizontal and vertical accuracy of the stereo model is $0.5 \mathrm{~m}$. The total accumulated error as a result of DTM construction and filtering was no higher than $1.0 \mathrm{~m}$ that meet the ICAO requirement for the object height accuracy determining at the OLS area (3.0m for vertical and $5 \mathrm{~m}$ for horizontal measurements).

\subsection{Geospatial modeling}

To obtain spatial data for subsequent geoinformation analysis, the next steps were completed on the stereo model:

1. The DTM of the aerodrome area (bare earth level) was created (Fig. 4.);

2. A three-dimensional dense OLS model was built (Fig. 5.);

3. The difference matrix determining the maximal permissible heights was obtained (Fig. 6.);

4. The maximal permissible obstacle contour lines with step section of $1.0 \mathrm{~m}$ were created (Fig. 7.).

As the results the accuracy of digital models, and data on the terrain and obstacles of aerodromes was $0.5-0.7 \mathrm{~m}$ (requirements - $3.0 \mathrm{~m}$ ) which meets the flight safety criteria. Geodetic accuracy of cartographic zoning model contours is $1.0 \mathrm{~m}$ that allows to obtain or plan the obstacle data with accordance to the ICAO requirements. 


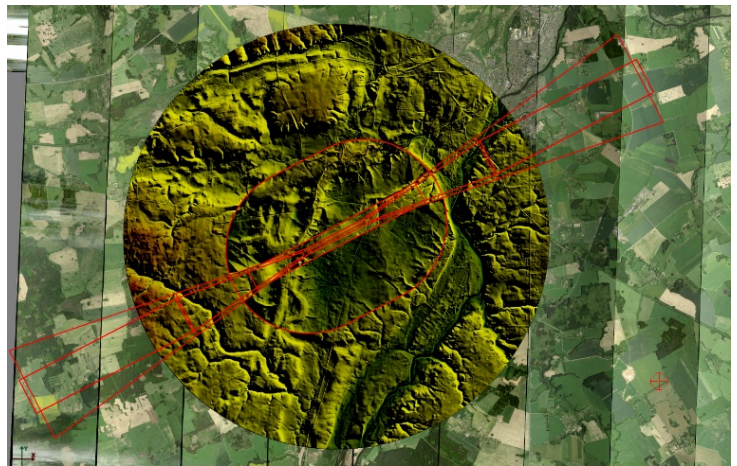

Fig. 4. DTM (bare earth level)

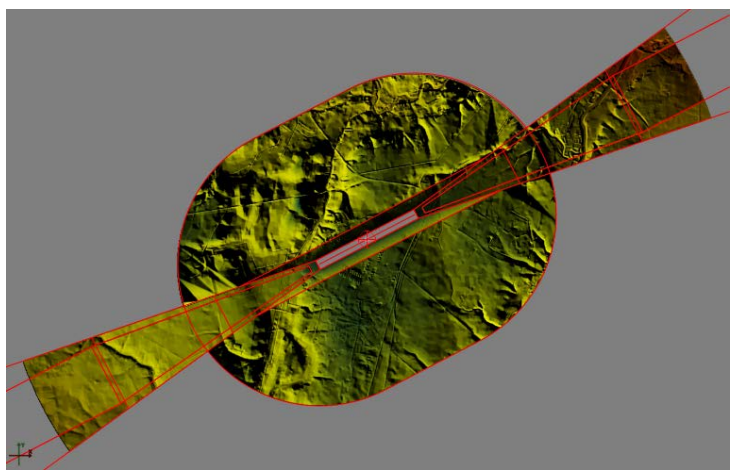

Fig. 6. Difference matrix

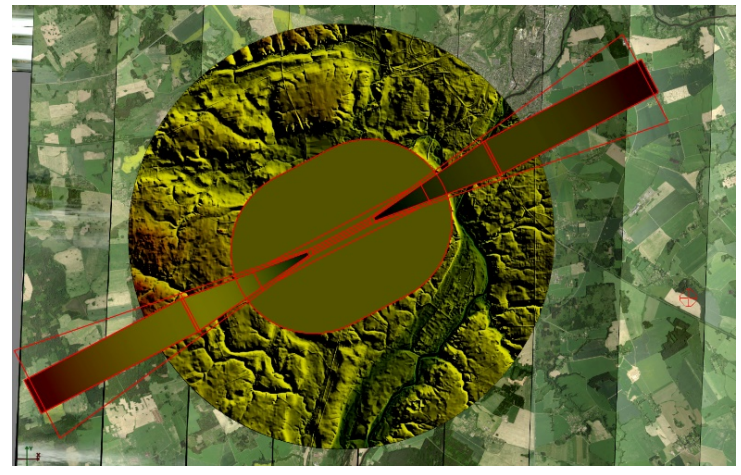

Fig. 5. DTM and dense OLS model

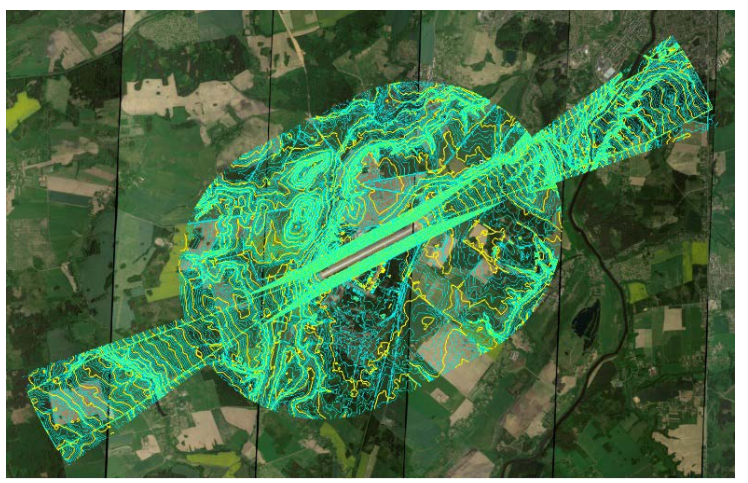

Fig. 7. Maximal permissible obstacle height contour lines 


\subsection{Geoinformation analysis}

Zone dimensions depend on the runway length. The runway length of ORSHA airfield is 6,000 feet, which implies the impact zones allocation of the largest dimensions. The aerodrome impact zones have been constructed in GIS ArcGIS using editing tools [18].

The aerodrome horizontal zoning has been enhanced with height limitation factor (Fig.8)

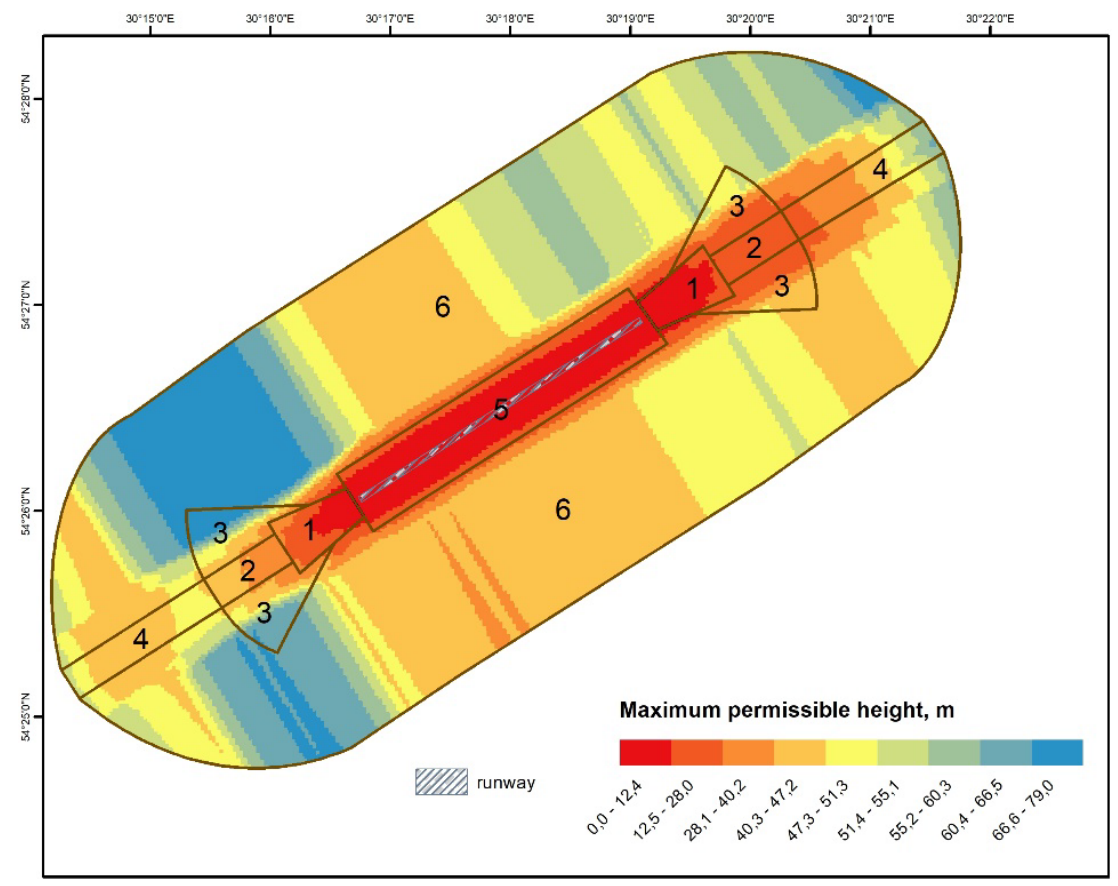

Fig. 8. Cartographic vertical and horizontal zoning model

1 - Runway Protection Zone; 2 - Inner Safety Zone; 3- Inner Turning Zone; 4- Outer Safety Zone; 5 - Sideline Safety Zone; 6- Traffic Pattern Zone

The vertical zoning has been implemented based on the difference matrix. The vector grid model covered the territory of aerodrome impact zones with cell size $10 \times 10 \mathrm{~m}$ was created. Each cell is characterized by belonging to the certain impact zone and its corresponding recommended land uses and restrictions. Also, for each cell, the maximum permissible height was determined. Thus, the developed vector model is the basis for further planning and developing aerodrome territory.

For forestry planning and management on the aerodrome territory the models of the forest stand permissible height and age have been developed. Pine as the most common tree species within the study area was used for modelling. Calculating of the forest stand age when trees reach the maximum permissible height was performed using the regression analysis. As the initial data normal yield tables of the pine stand was used [19]. The tables reflect the tree growth rate for Belarus bioclimate zones. The relationship between pine age and height is estimated by a third-degree polynomial (1):

$$
y_{\text {pine }}=0.003 x^{3}-0.0821 x^{2}+2.547 x-0.1523
$$


where $y=$ tree species maximum age; $x=$ maximum permissible height.

For a regression model, the coefficient of determination $\mathrm{R}^{2}$ is about $99 \%$.

The vector grid model was assigned with the attribute of the pine forest age in reaching the maximum permissible height (Fig. 9). The attributive field was filled in automatically using the ArcGIS Field Calculator and regression equation above.

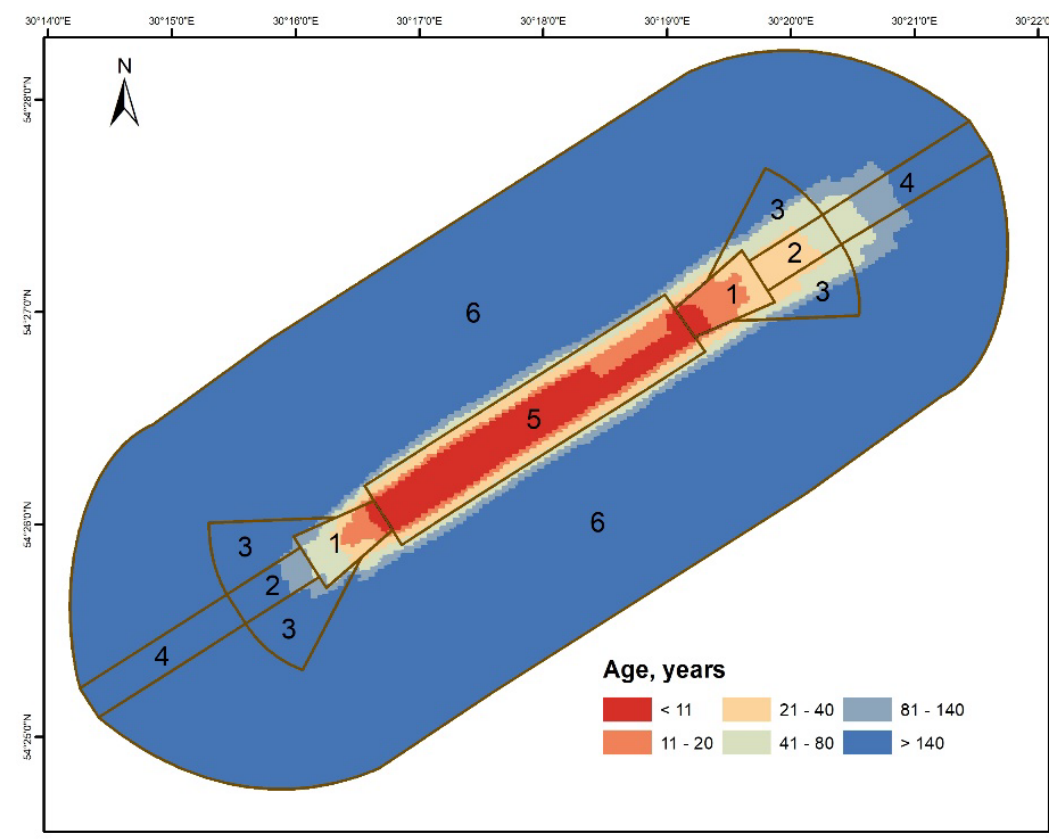

Fig. 9. The forest vegetation height and age limitation zones

1 - Runway Protection Zone; 2 - Inner Safety Zone; 3- Inner Turning Zone; 4- Outer Safety Zone; 5 - Sideline Safety Zone; 6- Traffic Pattern Zone

The model (Fig. 9) illustrates the location, where the pine forest can reach the felling age (more than 80 years). So, the revealed pattern will help land users to determine where any height of forest and park tree plantations will not affect flight safety, and where it is necessary to remove vegetation after reaching a certain age of trees.

\section{Results and discussion}

As the research main goal, methods of spatial modeling, geoinformation analysis using a stereo model, digital elevation models and obstacle limitation surfaces have been proposed for sustainable aerodrome land development and planning. For digital mapping and an aerodrome zoning models, were used digital elevation and limitation surfaces dense models, and a permissible obstacle height digital model, with a contour section of $1.0 \mathrm{~m}$ was built.

Using this model, it is easy to determine the age limits of forest plantations, as well as the boundaries of territories where there is no need to monitor forest obstacles in height. As a result of forecasting the height of forest vegetation in time according to the obtained model, there is no need for constant and laborious monitoring of forest obstacles during the primary or re-greening of the aerodrome territory. 
The main economic effect of the geospatial modeling and analysis methods is a significant reduction in the monitoring cost and its replacement by planning and forecasting. It can be easy predicted maximal height of vegetation permissible age, as well as confidence and reliability of the contours when placing zoning boundaries on the aerodrome area ground.

Thus, the integrated cartographic model defines the aerodrome area horizontal zones, considers the criteria for height limitations, as well as environmental and social factors. The joint cartographic model can be used in architectural design, construction, reconstruction of aerodrome facilities and the land use development assessment.

\section{References}

1. ICAO, Annex 14 Volume I.: International Standards and Recommended Practices for Aerodromes - Aerodrome Design and Operations, (8 ed.), ICAO, Canada (2018)

2. WSDT (Washington State Department of Transportation), Airports and compatible land use. Volume 1: An introduction and overview for decision makers., WA: Author, Seattle (1999)

3. FAA Office of Environment and Energy, Land Use Compatibility and Airports, a Guide for Effective Land Use Planning (2021)

4. L. Mitsevich, N. Zhukovskaya, 3D modeling and GIS analysis for aerodrome forest obstacle monitoring, Int. Arch. Photogramm. Remote Sens. Spatial Inf. Sci., XLIII-B22021, 753-757 (2018)

5. M.R. Contreras-Alonso, A. Ezquerra-Canalejo, E. Pérez-Martín, T.R. Herrero-Tejedor, S. López-Cuervo Medina, Environmental assessment of Obstacle Limitation Surfaces (OLS) in airports using geographic information technologies, PLoS One, 15 (2020)

6. C. Gomez, Y. Hayakawa, H. Obanawa, A study of Japanese landscapes using structure from motion derived DSMs and DEMs based on historical aerial photographs: New opportunities for vegetation monitoring and diachronic geomorphology, Geomorphology, 242, 11-20 (2015)

7. X. Yu, J. Hyyppä, H. Kaartinen, H. Hyyppä, M. Maltamo, P. Rönnholm, Measuring the growth of individual trees using multi-temporal airborne laser scanning point clouds, In Proceedings of ISPRS Workshop Laser Scanning Vol. 2005, 204-208 (2005).

8. ICAO, Doc 9184 AN/902 Airport Planning Manual. Part 2: Land Use and Environmental Control, (3 ed.), ICAO, Canada (2002)

9. N. Litvinka, Selection of spatial data and aspects of its photogrammetric plotting during digital terrain model of Belarusian aerodrome territory creation, Vestnik PSU, F, 16, 141-148 (2016)

10. S. Kriachok, Topographic and geodetic support of airports, Technical sciences and technologies, 1(11), 239-251 (2018)

11. A. F. Dankevych, S. Iu. Markov, V. A Babchenko, Problems of geodetic control of highrise objects at aerodromes and aerodrome territories, Bulletin of Geodesy and Cartography, 1, 4-7 (2005)

12. A. V. Volkov, V.V. Volkov, Requirements for providing the territories of state aviation aerodromes with large-scale topographic plans for land management and cadastral works, Astrahanskij vestnik ehkologicheskogo obrazovaniya, 2 (50), 149-155 (2019) 
13. O.A. Kartyshev, N.I. Nikolaykin, Criteria of the aviation noise assessment for aerodrome environs zoning of the airports and protective measures justification, Civil Aviation High Technologies, 20(3), 30-40 (2017)

14. O.A. Kartyshev, Sanitary zone definition in the airport vicinity on the base of «Aviation noise» factor, Civil Aviation High Technologies, 160, 141-147 (2010)

15. M.V. Butorina, Classification of airports by noise levels and noise protection levels, Noise theory and practice, 2(20) (2020)

16. I.A. Suhorukova, Setting boundaries of residential areas in the environs of airfields, Vestnik MGSU, 2 (2012)

17. A.P. Mikhailov, A.G. Chibunichev, Photogrammetry (MIIGAiK, Moscow, 2016)

18. ACRP research report 200, Using GIS for Collaborative Land Use Compatibility Planning Near Airports, Transportation Research Board and National Academies of Sciences, Engineering, and Medicine, (2019)

19. A.P. Kulagin, M.V. Kuzmenkov, A.V. Tarkan, R.S. Buzunovskij, Taxation and forest management reference book, Forestry and hunting, Minsk (2019) 